\title{
GENESIS - Generating e-learning systems in schools: School-university e-learning research partnerships for scaling up innovation
}

Cathy Hill

Head of Library \& Information Science K-12, St Paul’s Grammar School Penrith, Australia

Professor Shirley Alexander Dean of the Faculty of Education and Director of the Institute for Interactive Media and Learning, University of Technology, Sydney (UTS)

Karen Cuthbert St Ives North Public School, St Ives

Dr Robin Hall GENESIS Project Manager/Researcher, UTS: Education

Nerida McCredie PhD Candidate, UTS: Education

Norm Nicholson St Ives North Public School, St Ives North (now Principal, Killara Public School) Associate Professor Lynette Schaverien

UTS: Education

Dr John Tomkins St Paul's Grammar School, Penrith

Serena Vecchiet MLC School, Burwood

Despite optimism about new technologies for learning, e-learning innovation has been slow to scale up. This research set out to investigate whether an e-learning environment designed by students themselves would scale easily in schools. To do so, the GENESIS Project, a collaborative undertaking between three schools and a University, created the opportunity for students as researchers to conceive, prototype, and test an e-learning environment in which they and other students could explore ideas of interest to them. Preliminary findings show that students are able to design e-learning environments that provide good contexts for learning. Furthermore, such an approach appears to set in motion deep and lasting change in schools in ways that align with Coburn's (2003) four ways of thinking about scaling up. The Project demonstrates, in all its phases, a way in which students themselves can take information leadership of curriculum in a culture of change. 


\section{Introduction}

In this International Research Forum, we describe a collaborative e-learning research and development project (the GENESIS project: GENerating E-learning Systems In Schools) and present some preliminary findings. Over the last three years three schools (two Independent K-12 Schools and one State Primary School) and the University of Technology, Sydney (UTS) have been undertaking this large study, funded under the Australian Research Council Linkage scheme.

\section{Purpose of study}

A central objective for this research was to investigate whether a student designed e-learning environment would scale easily in schools. It is Coburn's (2003) view that though "the issue of 'scale' is a key challenge for school reform, ... it remains undertheorized in the literature." (p. 3) More particularly (and here she cites a long list of researchers who do so) she notes, "most research on scale tends to define what it means to 'scale up' an external reform in quantitative terms, focusing on increasing the number of teachers, schools, or districts involved".(p. 3) Though this quantitative definition appears to be a simple, intuitive and measurable way to understand scale, Coburn asks,

What does it really mean to say that a reform program is scaled up in these terms? It says nothing about the nature of the change envisioned or enacted or the degree to which schools and teachers have the knowledge and authority to continue to grow the reform over time. By focusing on numbers alone, traditional definitions of scale often neglect these and other qualitative measures that may be fundamental to the ability of schools to engage with a reform effort in ways that make a difference for teaching and learning. (p. 4)

Upon this critique, Coburn proposes an expanded conceptualisation of scale "comprised of four interrelated dimensions: depth, sustainability, spread, and shift in reform ownership (italics added)."(p. 4) It is in these expanded terms that we in the GENESIS project understand scaling up.

The slow scaling up of e-learning innovation is an instance of a much more general gulf between research and practice in Science and Technology education and education at large (Hurd, 1991; Tobias, 1999). Innovative and potentially successful elearning approaches do not often or easily become central parts of the systems for which they were developed (Alexander and McKenzie, 1998; Downes et al., 2000). Recognising an opportunity to address these challenges in a new way, the GENESIS Project strategy was conceived in tune with a recent shift in the ways knowledge is generated (Gibbons et al, 1994): moving away from laboratory-based development and subsequent dissemination in the field, to a model whereby knowledge consumers themselves develop knowledge in interdisciplinary teams in the context within which it is to be used.

So, the GENESIS Project created an opportunity for students (aged between seven and 15 years) as researchers, to conceive, prototype and test an e-learning environment in which they and other students could explore ideas and/or questions of central interest to them. 
A wide of range studies report students' ability to research and design in real-world contexts (Joseph, 2004) and to design educational games (Kafai, Franke, Ching \& Shih, 1998). Others show that students are well able to carry out sophisticated computing procedures (Downes, 1998) and to participate in Internet-related activities such as net-surfing, information retrieval, e-mail and chat rooms (Kafai \& Sutton, 1999). Yet few have sought to explore students' ability to design their own software.

Web-based education programs are usually created by commercial developers, with little consultation with students and teachers. For example, The GLOBE Program encourages young people to explore a topic selected by others (how the environment works), drawing from data prepared by others (such as atmospheric research corporations) in a site managed by others (such as NASA) (see http://www.globe.gov/).

Over recent years, researchers have sought to explore the design capabilities of students in the area of information and communication technologies. Rather than providing students with educational software designed by content specialists and programmers, Kafai and Ching (1998) explored the design practices of student simulation teams as they collaboratively created and implemented software in a topic area selected by the teacher (neuroscience). Findings showed that students approached the planning sessions having already experienced software design.

Other studies have shown that students are well able to identify cutting-edge concepts and to exploit ready-made software to deepen their understanding of them. In Loh, Reiser, Radinsky, Edelson, Gomez and Marshall's (2001) study high school students used the simulation environment Interactive Physics to set up computer simulations with different configurations of planets orbiting the sun. They wanted to determine whether the planets have an effect on Pluto's orbit. The teachers provided the students with a range of software options and students were required to use the computer both as a data exploration and analysis tool, and as a tool to construct and present their findings.

The approach used in the GENESIS Project builds on such research but with some significant differences. Rather than providing students with a teacher-selected topic or with already developed software with which to explore it, here students selected an area of knowledge they were passionate about understanding, devised their own ways of gathering, analyzing and reporting information about the topic and then, designed and developed an e-learning environment which provokes and supports deep and lasting engagement.

\section{Methodology}

The GENESIS Project progressed through five phases.

In Phase One, students were encouraged to pose their own deep and interesting questions, which might serve as the knowledge focus for their e-learning environment. Students generated 'big questions' which they felt were highly relevant to their lives in today's world, and clustered them as follows:

Human Body: How do different medicines work?

The Universe: What is gravity and how is it involved with the pattern and movement of stars and planets in our universe? What happened at the Big Bang and is space really empty?

Human Brain: Why do we think and how do we think? How come we're not born with the knowledge we know now? 
Across schools consensus was then reached within the student body on the cluster pertaining to the working of the human brain: How and why do we think? How come we're not born with all the knowledge we know now?

In Phase Two, students generated their own connections with this 'big question' planning smaller, more focused investigations about the human brain. For example, students at one school were interested in the following set of questions:

- How does the brain work?

- How does the brain function?

- How do we dream? What happens when we dream?

- How and why do we forget? How and why do we remember?

Supporting materials for students in this phase of the process included an Investigation and Design Kit and the creating of a Team GENESIS website. These sought to assist students in refining questions and in framing and conducting actual investigations that might yield some answers to their questions. Student groups themselves posed a range of different questions they considered fruitful if they were to try to answer their big question and they suggested diverse kinds of enquiries in a variety of contexts (for example, gender differences, mother/child attachment, word/colour recognition and dreams). As a part of their investigations, students collected material and developed ideas about how an e-learning environment might allow others to engage with their questions.

In Phase Three, students used their findings to design a GENESIS Journey website as follows: Travellers begin their journey at the Village Square, where they are able to view videos at the Cinema, leave messages, comments and ideas on Discussion Boards at the Post Office and play games at the Internet Café. They may continue their journey to any of the 18 Houses named for its investigation focus such as Dreams House, Jacob the Rat's House, Obstacle Course House and Children Playing House. The travellers may store ideas in their personal Notepad. Within each House travellers may engage with the designers' investigations and interact with other students visiting the house via the Discussion Board. Programmers and software designers from the Institute for Interactive Media and Learning at University Technology, Sydney (UTS) then worked in close communication with the students to produce and professionally fine-tune the site.

In Phase Four, students from each of the participating schools undertook their own inquiry into the effectiveness of the GENESIS journey as a learning environment. To do so, they used a variety of methods including surveys, observations and interviews.

In Phase Five, scaling was undertaken as a collaborative process, in tune with the Project's emphasis on collaboration. At the outset, three in-school planning workshops were held at which students and teachers considered a school strategy for working with the GENESIS Learning Journey. At one school Year Four students chose to undertake their own further investigation about space. At another, teachers chose to depart from their teaching methods to adopt the approach used in GENESIS to teach a curriculum topic.

The third school put in place plans to prepare a storyboard using video recordings made by students in the course of their GENESIS investigations to deepen other students' and staff's understanding of the Project and as well, to timetable opportunities for high school students to investigate curriculum topics using the GENESIS process. 
Whilst having some of the features of action research, the GENESIS project's methodology conforms to a new and increasingly well-accepted educational research paradigm, now being labeled design-based research. Such research "blends empirical educational research with the theory-driven design of learning environments, [thereby fashioning] an important methodology for understanding how, when and why educational innovations work in practice" (The Design-based Research Collective, 2003, p. 5). A cutting-edge, generative theory of learning (Schaverien and Cosgrove, 1999, 2000) guided the learning and teaching approaches used in the students' investigations at the core of the Project as well as the research strategy in which these investigations were embedded.

\section{Preliminary Findings}

Already findings suggest that students are able to design e-learning environments that provide good contexts for learning. Students have engaged in learning arising directly from their own questions and interests. They have raised important issues, shown research capability, pursued significant avenues of investigation and thought critically about their big question. Student interest and participation have generally been high across the student population, though student researchers have noted and offered explanations for variations in student immersion in the GENESIS Journey according to age.

Each school approached scale up according to its own needs and strategies. One school responded to students' passionate curiosity about a topic they had earlier identified as highly relevant in today's world (space). Here, Year Four students posed 400 wide-ranging questions about the topic and then they devised, what they called, an ODYSSEY journey, exploring questions of particular interest (such as, Is there such a thing as alien life? Why do some planets have rings and others don't? What are black holes and where do they lead?). In order to exploit knowledge in the community, they invited local astronomers to the school and held a Space Fair for family members and staff. Another school provided students with the opportunity to investigate the curriculum topic of wetlands in new ways in the context of their classroom. The other school continues to consider how teachers and students might be informed about the GENESIS way of doing things and how high school students might learn using such an approach.

\section{Conclusions}

In many respects, the GENESIS Project appears to have seeded a significant cultural change in participating classrooms. For example, the more students investigated their questions, the more they realised they needed to ask: students realised that those specific answers often expected in the delivery of conventional classroom curricula could be premature and even inappropriate here. The GENESIS Project appeared to set up the conditions within which students could pursue their natural curiosity about the world within the constraints of a classroom, by enabling them to move beyond their local environment and engage with others in a virtual world they had created. Furthermore, the effectiveness of such an approach appeared to set in motion deep and lasting change in schools in ways that align with Coburn's (2003) four ways of thinking 
about scaling up, not just in terms of spread but as well, sustainability, depth and shift in ownership. The Project demonstrates, in all its phases, a way in which students themselves can take information leadership of curriculum in a culture of change.

\section{Acknowledgements}

The GENESIS project was supported by substantial cash contributions from MLC School and St Paul's Grammar School, matched funding from the Australian Research Council through its Linkage Scheme and large in-kind contributions from all three partner schools. We gratefully acknowledge the work of a small group of dedicated teachers across the three schools. We owe a sincere debt of gratitude to the students for their enthusiasm and their insights: these have been the lifeblood of the project. 


\section{References}

Alexander, S. \& McKenzie, J. (1998). An Evaluation of Information Technology Projects for University Learning. Report of the Committee for University Teaching and Staff Development, Canberra: AGPS.

Coburn, C. E. (2003), Rethinking scale: Moving beyond numbers to deep and lasting change. Educational Researcher, 32(6), 3-12.

Downes, T. I. (1998). Children's use of computers in their homes. Unpublished doctoral dissertation, University of Western Sydney, Macarthur, Australia.

Downes, T., Fluck, A., Gibbons, P., Leonard, R., Matthews, C., Oliver, R., Vickers, M., \& Williams, M. (2000, December). Models of teacher development for the integration of information and communication technologies into classroom practice: Research in progress. Paper presented at the NZ-AARE annual conference, University of Sydney.

Joseph, D. (2004, Fall). The practice of design-based research: Uncovering the interplay between design, research, and the real-world context. Educational Psychologist, 39(4), 235 - 242.

Kafai, Y. B., \& Ching, C. C. (1998, December). Talking science through design: Children's science discourse within software design activities. Paper presented at the International Conference of the Learning Sciences at the Georgia Tech University, Atlanta, Georgia.

Kafai, Y. B., Franke, M. L., Ching, C. C., \& Shih, J. C. (1998). Game design as an interactive learning environment for fostering students' and teachers' mathematical inquiry. International Journal of Computers for Mathematical Learning, 3, 149-184.

Kafai, Y. B. \& Sutton, S. (1999). Elementary school students' computer and internet use at home: Current trends and issues. Journal of Educational Computing Research, 21(3), 345-362.

Gibbons, M., Limoges, C., Nowotny, H., Schwartzman, S., Scott, P., \& Trow, M. (1994). The new production of knowledge. London: Sage.

Hurd, P. (1991). Issues in linking research to science teaching. Science Education 75(6): 723-732.

Loh B., Reiser B.J., Radinsky J., Edelson D.C., Gomez L.M., \& Marshall, S. (in press). Developing reflective inquiry practices: A case study of software, the teachers, and students. In K. Crowley, C. Schunn, and T. Okada (Eds.). Designing for science: Implications for everyday, classroom and professional settings (pp. 279-323). Mahwah, NJ: Erlbaum.

The Design-Based Research Collective (2003). Design-based research: An emerging paradigm for educational inquiry. Educational Researcher, 32(1), 5-8.

Schaverien, L. \& Cosgrove, M. (2000). A biological basis for generative learning in technology-andscience: Part II-Implications for technology-and-science education. International Journal of Science Education 22(1):13-35.

Schaverien, L. \& Cosgrove, M. (1999). A biological basis for generative learning in technology-andscience: Part I - A theory of learning. International Journal of Science Education 21(12):1223-1235.

Tobias, S. (1999). Some recent developments in teacher education in mathematics and science: A review and commentary. Journal of Science Education and Technology 8(1): 21-31.

\section{Author Note}

Cathy Hill has held the position of Head of Library and Information Science K-12 at St Paul's Grammar School, an International Baccalaureate School, for the last $51 \frac{2}{2}$ years. Prior to this position she held positions in two primary school libraries, one in an independent school and the other, in a NSW government school. Cathy has been a partner investigator in the GENESIS Project since 2003. 
Reproduced with permission of the copyright owner. Further reproduction prohibited without permission. 